\title{
Higher Education Instructors' Usage of and Learning from Student Evaluations of Teaching - Do Achievement Goals Matter?
}

\author{
Julia Hein \\ University of Mannheim \\ Martin Daumiller \\ University of Augsburg
}

\author{
Stefan Janke \\ University of Mannheim \\ Markus Dresel \\ University of Augsburg
}

\author{
Raven Rinas \\ University of Augsburg \\ Oliver Dickhäuser \\ University of Mannheim
}

\begin{abstract}
Identifying what motivates higher education instructors in their self-regulated learning from student evaluations of teaching (SET) is important for improving future teaching. In a longitudinal online field study, we investigated how higher education instructors' achievement goals predict the use of SET(s), processing its results and learning from it. We expected beneficial effects of learning (approach and avoidance) goals and performance approach goals, while performance avoidance goals and work avoidance goals should be detrimental for the learning process. In total, 407 higher education instructors with teaching commitments reported their achievement goals. Out of these participants, 152 instructors voluntarily conducted SET(s) and subsequently reported their learning intentions regarding this student feedback. Using structural equation modelling, we found that learning avoidance goals were positively associated with conducting SET(s) and learning approach goals were positively associated with learning intentions. These findings highlight the importance of learning goals for instructors' use of SET(s).
\end{abstract}

Keywords: achievement goals, instructors, professional learning, student evaluations of teaching, higher education

THIS PAPER IS SUBMITTED FOR PUBLICATION.

Please do not cite or distribute any portion without authors' permission.

Student evaluations of teaching (SETs) are used in a wide range of universities and higher education institutions as a tool to provide valuable feedback to instructors (Marsh \& Roche, 1993; Wagenaar, 1995; Zhao \& Gallant, 2012) and serve the purpose of improving teaching (Nowakowski \& Hannover, 2015). The implementation of SETs can improve teaching effectiveness (Serin, 2019), especially if the feedback given in the SETs is complemented by external consultation (Marsh, 1984; Marsh \& Roche, 1993). Nevertheless, the impact of SETs likely depends on instructors' willingness to use and process student feedback for the development of their teaching (Kember et al., 2002). From our view, instructors should have a proactive role

Correspondence concerning this article should be addressed to Julia Hein, Chair of Educational Psychology, University of Mannheim, A5,6, 68159 Mannheim, Germany; julia.hein@uni-mannheim.de.

We have no known conflicts of interest to disclose.

The research reported in this article was supported by the German Research Foundation (Deutsche Forschungsgemeinschaft; DFG): Grant DR 454/8-1 awarded to Markus Dresel and Grant DI 929/51 awarded to Oliver Dickhäuser. We would like to thank Jan Siebert and Hannes Kohlsaat for their technical support in our study. in generating and using feedback, similar to assumptions regarding students (see Molloy \& Boud, 2013; Boud \& Molloy, 2013). Therefore, we raise the question of what individual characteristics might prevent instructors from using SETs for the improvement of their teaching. To this end, little research has been conducted thus far concerning how instructors process SET-results or the factors that trigger their intentions to learn from it and change their teaching behavior. Such research is important as instructors need to actively engage with SETs by interpreting and internalizing the given information to be able to develop their teaching (compare Nicol \& Macfarlane-Dick, 2006; Ivanic et al., 2000 , for the use of feedback in school students). This active engagement in SETs that represents a self-regulated learning process mandates motivation, which resonates well with the emerging evidence that university instructors' achievement goals for teaching are associated with their engagement in professional learning (Daumiller et al., 2020). Particularly, learning goals (i.e., striving to develop professional competencies) predict professional learning (Diethert et al., 2015; Hein et al., 2019, 2020, see also Nitsche et al., 2013 for school teachers). Here, we propose a model that might explain why and how university instructors' teaching- 
related achievement goals are important predictors for the use and processing of SETs.

\subsection{Achievement Goals as Antecedents of Learning With and From SETs}

Achievement goals are future-focused cognitive representations of competence-related results or end states that an individual is committed to either avoid or approach (Hulleman et al., 2010; Payne et al., 2007). In line with prior research in the teaching domain, we distinguish between learning approach (focus on developing competence), learning avoidance (focus on avoiding not developing own competencies to the fullest extent), performance approach (focus on being perceived as competent), performance avoidance (focus on avoiding appearing incompetent), and work avoidance (focus on effort reduction by engaging in tasks with as little effort as possible) goals (see Butler \& Shibaz, 2008; Butler, 2014; Daumiller et al., 2019; Retelsdorf et al., 2010). Even though research on higher education instructors' achievement goals is still a young field of research (Daumiller, Stupnisky, et al., 2020), there is first evidence that higher education instructors' achievement goals guide their behavior (e.g., teaching quality and professional development) and predict emotions as well as cognitions (Daumiller et al., 2019; Diethert et al., 2015; Hein et al., 2019; Janke \& Dickhäuser, 2018; Rinas et al., 2020).

Regarding the use and processing of SETs, achievement goals may act as a lens that filters the perception of students' feedback as a potential asset or obstacle for goal striving (in line with Kaplan \& Maehr, 2007; Nicol \& Macfarlane-Dick, 2006). Consequently, achievement goals might explain how instructors interpret the feedback situation (e.g., as a learning opportunity, an opportunity to appear competent, a risk of appearing incompetent, or an effort that could be reduced) and how they profit from student feedback. This impact of achievement goals could occur in different phases of the self-regulated learning process. Even if SETs are mandatory, instructors still need to process them on their own and use the results to evaluate potential effects of their goal striving. Models of self-regulated learning differentiate between pre-action, action and post-action phases of the learning process (e.g., Schmitz \& Wiese, 2006; Zimmerman, 2000). In the pre-action phase, instructors' motivation determines the initiation of the learning activity by deciding and planning to conduct an SET (if SETs are not mandatory). Here, it seems particularly important whether or not instructors see SETs as beneficial tools for their goal striving. During the action phase, instructors process the SET-results and likely need to interpret how these results align with their own achievement goals to draw relevant conclusions for their teaching (Butler \& Winne, 1995; Nicol \& Macfarlane-Dick, 2006). Finally, in the post-action phase, instructors reflect on what they have learned and form intentions about how to further improve their teaching in a way that helps them reach their achievement goals. These learning intentions may eventually lead to changes in the actual teaching behavior, and thereby, the teaching quality (in line with Achtziger \& Gollwitzer, 2018; Ajzen, 1991). We will now investigate exactly how achievement goals impact the different phases of self-regulated learning, as the learning result is dependent upon on instructors' engagement (and motivation) in each of these phases (Schmitz \& Wiese, 2006; Zimmerman, 2000).

\subsection{Different Classes of Achievement Goals and Learning from SETs}

Learning approach goals facilitate the active search for learning opportunities, which are key for the development of competencies. Indeed, prior studies have shown that learning approach goals are closely tied to engagement in formal and informal learning activities in a variety of contexts (Cerasoli et al., 2018; Choi \& Jacobs, 2011; Diethert et al., 2015; Nitsche et al., 2013). Learning approach goals are positively associated with the intention to participate in formal trainings of employees in academia (pre-action phase, see Diethert et al., 2015), engagement within formal professional training courses (action phase, see Daumiller et al., 2020), as well as with learning results in adult samples (post-action phase, Payne et al., 2007). As such, we assume that learning approach goals have a beneficial impact on all steps of self-regulated learning. For SETs, this means that we can assume that learning approach goals are associated with instructors' willingness to conduct SETs, their effort to process the feedback, as well as the development of learning intentions. While learning avoidance goals have sparked scientific debate about their relevance for learning processes (Cury et al., 2006; Hulleman et al., 2010), prior research has suggested that they may be beneficial for instructors' teaching and professional learning (Daumiller et al., 2019; Hein et al., 2020). We consider it to be a distinct possibility that the striving to avoid missing a learning opportunity could enhance instructors' vigor to use and process students' SETs. 
Asking students for feedback through SETs does not only constitute a learning situation, but also a performance situation for instructors. Specifically, we assume that SETs may help instructors to comprehend whether they appear competent in the eyes of their students (appearance is a core component of instructors' performance goals, see Daumiller et al., 2019). ${ }^{1}$ Performance approach goals can be seen as a preference to attain favorable judgments of teaching-related competence which is grounded in high competence expectancies, whereas performance avoidance goals might be interpreted as a preference to avoid unfavorable judgments (Elliot \& Church, 1997). This means that performance approach goals could motivate instructors to engage in SETs to receive praise, whereas performance avoidance goals could motivate them to abstain from using SETs, given the danger of receiving self-diminishing feedback. In sum, we consider both performance approach and avoidance goals as predictors for the initiation of the learning process (pre-action phase). However, we do not have directed hypotheses regarding the association of performance goals and the processing of SET-results (action phase). In addition, we do not expect performance goals to facilitate further learning intentions (post-action phase), congruent with prior research on adult learning (Payne et al., 2007).

Finally, a negative association between work avoidance goals and learning from SETs is highly plausible. Since all necessary steps for using SETs and learning from their results can be considered to be effortful in nature, teaching-related work avoidance goals should be detrimental for the whole learning process. In line with this assumption, empirical studies with school teachers suggest that work avoidance goals are associated with a lower number of attended training workshops (Nitsche et al., 2013), and less engagement in professional training courses (Daumiller et al., 2020).

\subsection{Mediation Processes in Self-regulated Learning from SETs}

Following models of self-regulated learning, we assume that the impact that achievement goals have on early phases of the learning process also impact the later phases. In other words, if achievement goals hinder instructors to engage in SETs, they cannot process SETs in the first place. Moreover, if instructors invest more effort to process SETs, they will also find more

\footnotetext{
${ }^{1}$ Since SETs contain students' reports regarding their perception of the instructors' competencies, we assume that especially the appearance component of performance goals is relevant for predicting
}

possibilities to form learning intentions. While it is trivial that the lack of an SET directly corresponds to being unable to process SETs, the association between processing and learning intentions should be further tested. We expect such mediation processes to be important for the impact of learning goals, which are meant to provide the necessary motivation to develop intentions based on the information in the SETs. Moreover, the maladaptive impact of work avoidance goals on learning intentions might be mediated through an insufficient processing of SET-results. We do not expect such mediations for performance goals.

Prior research supports the existence of mediation processes alongside the assumption of models of self-regulated learning. In student samples, positive associations between motivation and performance have been mediated by engagement using video hits as an objective quantitative measure in massive open online courses (Barba et al., 2016). Student teachers' acquisition of pedagogical knowledge (post-action phase) have also been found to depend on the usage of learning opportunities in the action phase (Watson et al., 2018). For instructors specifically, studies have shown that learning engagement (in the form of intensity and elaboration) mediates the associations between learning approach goals/work avoidance goals and learning gains within professional training courses (Daumiller et al., 2020). Moreover, self-reported learning time for formal and informal leaning activities has been found to mediate the positive associations of learning (approach/avoidance) goals with self-reported learning results (Hein et al., 2019, 2020). Moreover, learning goals positively and work avoidance goals negatively, relate to observed attention (Kücherer, 2020). However, the informative value of prior research on this mediation process within samples of instructors may be limited by the same method bias, as most constructs were assessed by self-report-measures. In our research, we thereby want to show that mediation processes which bridge different phases of self-regulated learning exist by using objective indicators of the learning activity to overcome these methodological limitations in research on instructors' professional learning.

the use of SETs. Consequently, we focus on the appearance component of performance goals within our study. 


\subsection{Moderators of the Impact of Achievement Goals on Learning from SETs}

The validity of SETs is strongly debated within the literature and, as such, also among higher education instructors (Hornstein, 2017; Marsh, 1984; Spooren \& Mortelmans, 2006). As a result, instructors may differ in their beliefs about SETs to be appropriate measures of teaching quality that can be used as tools to advance their teaching or not. Such beliefs may thereby influence whether instructors voluntarily use SETs. Beliefs can be seen as conditional knowledge that can be interpreted as if-then rules (Butler \& Winne, 1995). If instructors believe in the validity of SETs, then they should be more likely to rely on them as they consider students' feedback to constitute valid and realistic information about their teaching quality. However, if instructors believe that students cannot assess teaching quality, then they will not ask students for their opinion on their performance in class in the first place. Besides direct effects on SET usage, we also assume that instructors' beliefs in the validity of SETs may moderate effects of achievement goals. Specifically, SETs can only be seen as a learning opportunity if instructors believe in the validity of student evaluations. Therefore, the positive link between learning goals and the use of SETs should be stronger given these validity beliefs. If, however, SETs are not seen as valid judgments, learning goals should not affect the decision to ask students for feedback.

Additionally, instructors may differ in the degree of psychological threat that they experience from negative feedback. This could have direct, negative effects on the likelihood of using SETs, and at the same time, might also moderate the impact of learning goals. If the general experience of threat through negative feedback is strong, this might hinder instructors from pursuing their learning goals by asking their students for feedback, because this situation entails the possibility of attaining negative judgments. This may especially be the case when considering that instructors could use other learning opportunities to improve their teaching and pursue their learning goals (e.g., formal learning opportunities such as didactical courses). To sum up, the general experienced threat through negative feedback might weaken the link between learning goals and the behavior of asking students for feedback.

\subsection{Present Research}

We aim to shed light on whether and how instructors' achievement goals impact learning from SETs during different phases of self-regulatory learning (pre-action $=$ decision to use and conduct SETs; action = processing of SETs; post-action = learning intentions for future teaching, see Figure 1). Regarding the pre-action phase, we assumed that learning approach goals, learning avoidance goals, and performance approach goals positively predict whether instructors voluntarily conduct SETs. In contrast, we assumed that performance avoidance and work avoidance goals negatively predict whether university instructors voluntarily conduct SETs. Furthermore, we expected that the strength of the

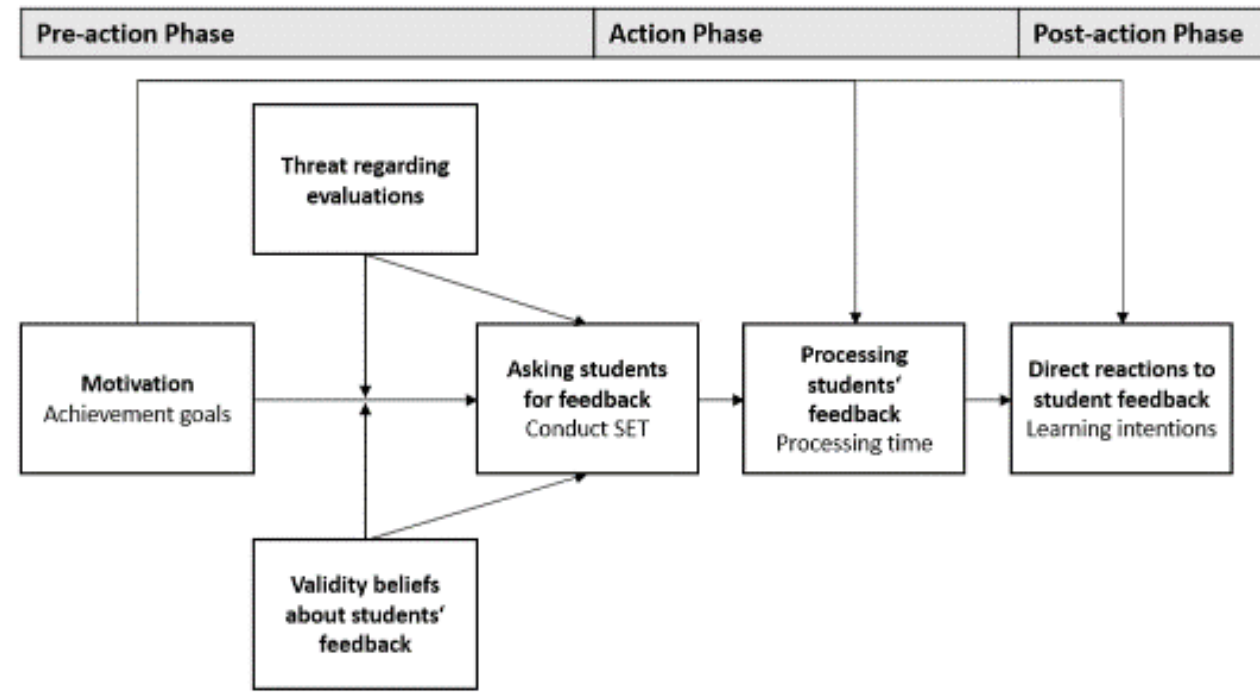

Figure 1. Theoretical model for the usage of SETs as a learning situation. 
association between learning goals and the usage of SETs is moderated by beliefs in the validity of SETs and the degree to which negative feedback is experienced as threatening. More precisely, the more instructors perceive SETs as valid measures of teaching quality and the less they feel threatened by negative feedback in general, the stronger the associations should be. Besides these moderation effects, we also assumed that beliefs in the validity of SETs positively predict, and experiencing threat after negative feedback negatively predict voluntary SET use directly.

Focusing on the later learning phases, we assumed that both learning approach and learning avoidance goals positively predict the time spent processing student feedback (as an objective measure of effort) in the action phase as well as learning intentions in the post-action phase. In contrast, we expected work avoidance goals to negatively predict these variables. We also expected that the time spent processing student feedback would mediate the associations between learning approach/avoidance and work avoidance goals and the postulated post-action phase outcome variable (learning intentions).

\section{Methods}

We conducted a longitudinal field study to investigate our research questions. In this study, we used data from an online open-access site (www.lehr-evaluationonline.de) that allowed instructors to administer SETs for their courses. We used a mixture of self-reports (achievement goals, learning intentions) and objective behavioral data (conducting SETs with the online tool, time spent processing the SETs) to investigate how achievement goals impact the different phases of selfregulated learning from SETs.

\subsection{Procedure}

The open-access platform was designed for the purposes of this study (Janke et al. 2020) and advertised at 21 higher education institutions in Germany and Austria through direct mail inquiries (total reach = 18,084 instructors). The participation in this study was voluntary for all instructors. After registering, all participants were asked to answer a baseline questionnaire. After finishing this baseline questionnaire, participants were prompted to register

\footnotetext{
${ }^{2}$ As end of March 2020 constitutes the end of the first semester of study participation for all instructors, we retrieved our data then. Later data cannot be used to test the hypotheses presented within
}

their courses for SETs within the online platform. Instructors voluntarily used this option. The instructors were allowed to evaluate as many courses as they wanted and could also use the evaluation tool after the first semester of study participation. In Germanspeaking countries, SETs are not typically linked to immediate consequences within the higher education institution. However, they are an important feedback, relevant for later job applications and tenure. To administer the SET itself, we used a well-validated scale (SEEQ; Marsh, 1982). Access to the questionnaire was given to the students via codes that were either distributed via mail or printed out by the instructors. After the evaluation, the SET-results were presented to the instructors online. We advised them to process the results of the SET for the first time when they had sufficient time to so. Immediately after processing the SET-results online, instructors were invited to answer a short questionnaire on their learning intentions. The data of the two questionnaires and the anonymized data derived from the platform was matched using electronically generated codes. We assured the participants that their answers would remain confidential and would only be used for scientific purposes. The instructors received incentives for their participation in every questionnaire (choice between a direct monetary reward or a donation to charity organization; 5 Euro [approx. 6 US $\$$ at that time] per questionnaire).

\subsection{Sample}

Overall, 796 instructors (412 male, 372 female, 12 diverse) registered for the online platform by the end of March $2020^{2}$ (response rate around 4\%), while 458 of these instructors finished the first questionnaire (participation rate: $57 \%$ ). We deleted the data of 16 instructors who did not assert that we can use their data for research purposes, and excluded one instructor who had no code for matching the data. We excluded further 34 participants who did not report a teaching commitment for at least one course within the semester of study participation from our analyses, as they did not have the opportunity to evaluate a course, which was a requirement for the study.

This resulted in a net sample of 407 Austrian and German higher education instructors $(52.6 \%$ male, $46.4 \%$ female, $1.0 \%$ diverse; average age: 38.60 years, Min =

this study, as this data might be biased by the sudden shift to digital teaching as a reaction to the COVID-19 pandemic. 
20 years, Max $=75$ years, $S D=10.21$ years) with baseline data and teaching commitment. The instructors had an average of 8.91 years of teaching experience $(\mathrm{Min}=$ $0, \operatorname{Max}=42, S D=8.38,0.2 \%$ missing data). They were employed in a wide array of disciplines, mostly in public universities $(94.3 \%)$ but also in other higher education institutions $(5.1 \%, 0.5 \%$ missing data). The sample consisted of $40.8 \%$ instructors without $\mathrm{PhD}, 44.0 \%$ instructors with $\mathrm{PhD}$ and $15.2 \%$ full professors (no missing data). It is important to note that instructors without $\mathrm{PhD}$ are predominantly members of the academic staff (and not doctoral students) in Germany and Austria, and therefore take on tasks in research, teaching, and administration in the same way as other instructors in higher education.

Out of the 441 instructors with baseline data, 152 instructors conducted at least one evaluation within the same semester. These instructors participated with 171 courses overall ( $\mathrm{n}=1672$ students). The subsample of 152 instructors $(50.0 \%$ male, $49.3 \%$ female, $0.7 \%$ diverse; average age: 38.68 years, $\operatorname{Min}=20$ years, Max = 65 years, $S D=10.24$ years), who conducted at least one SET, did not differ significantly in age $(U=19097.50$, $Z=-.114, p=.909)$, academic status $(U=18774.50, Z$ $=-.574, p=.566)$, or teaching experience $(U=$ $18659.50, Z=-.565, p=.572)$ compared to those instructors who did not conduct SET(s), based on ManWhitney-U-Tests.

\subsection{Measures}

\subsubsection{Baseline Questionnaire}

Achievement Goals in Teaching. Higher education instructors reported their current teaching-related achievement goals with a well-validated questionnaire (Daumiller et al., 2019). All items used the item stem "In my current teaching activities...". We assessed instructors' learning approach (e.g., "...I want to constantly improve my competences"; $\omega=.93$ ), learning avoidance (e.g., "... it is important to me to avoid having my competences not develop further"; $\omega=.90$ ), performance (appearance) approach (e.g., "...I want to be perceived as competent"; $\omega=.89$ ), performance (appearance) avoidance (e.g., "...I want to avoid being perceived as incompetent"; $\omega=.94)$, and work avoid-

\footnotetext{
${ }^{3}$ We assessed further goals that can be distinguished in instructors according to previous literature (Daumiller, Dickhäuser, et al., 2019). However, as we had no hypotheses for these further differentiated goals, we do not report on them within this paper.

${ }^{4}$ The SET-results consisted of quantitative and qualitative student feedback. The scale scores for the SEEQ scales (e.g., learning/value
}

ance goals (e.g., “...I want to have as little to do as possible"; $\omega=.95)$ on each four items. ${ }^{3}$ All items were answered on Likert-type scales ranging from 1 (do not agree at all) to 8 (agree completely).

Beliefs in the Validity of SETs. We used a slightly adapted scale measuring beliefs in the validity of SETs (Nowakowski \& Hannover, 2015) to assess how strongly instructors believe that students can capture teaching quality in general (e.g. "I believe that students are able to realistically assess the teaching quality of a course.", $\omega=.84)$. All items were answered on Likerttype scales ranging from 1 (do not agree at all) to 5 (agree completely). High scores represent positive beliefs in the validity of SETs and imply that instructors are convinced that student evaluations are valid indicators of teaching quality.

General Experienced Threat Through Negative Feedback. To assess instructors' general experienced threat through negative feedback, we used a threat subscale of a well-validated questionnaire (Gaab, 2009) that refers to threat experience within concrete situations. The concrete situation needs to be described before displaying the items. We specified the concrete situation by asking the instructors how they feel when they receive negative feedback about their teaching from students or colleagues with four items (e.g., "Negative feedback is very unpleasant for me."; $\omega=.79$ ). All items were measured with a Likert-type scale ranging from 1 (completely wrong) to 6 (entirely true). High scores represent stronger experienced threat through negative feedback.

\subsubsection{Behavioral Data (Derived from the SET-Plat- form)}

Processing Time Regarding SET-results. The processing time, more precisely, the time that instructors had left the evaluation results open for online (in the displayed tab in their browser) before starting the second questionnaire, was tracked as log data within the system measured in milliseconds. This measure accurately indicates the time that the SET-results ${ }^{4}$ were viewed for. To facilitate interpretation of the time stamps, we converted the data from milliseconds into minutes. Furthermore, we identified outliers which could indicate that instructors had left the tab window open while being away from their desk or doing other

or group interaction), single items on student background characteristics (e.g., prior subject interest), and open comments by students (e.g., what they liked and what can be improved within the evaluated course) were presented online. 
tasks. More specifically, we replaced extremely high processing times (above 2 hours) for 19 participants with missing values.

\subsubsection{Second Questionnaire (Filled out Immediately After Processing the SET)}

Learning Intentions. We used both quantitative and qualitative measures to assess learning intentions. We used a slightly adapted German self-report scale (Nowakowski \& Hannover, 2015) as a quantitative measure for the intention to act on SET-results. The self-report scale captures the intention to discuss the concrete SET-results with students and colleagues, to make changes in future courses, and participate in didactical trainings with six items (e.g., "Based on this feedback I will make concrete changes to my course."; $\omega=.65$ ). All items were answered on Likert-type scales ranging from 1 (do not agree at all) to 5 (agree completely). Furthermore, we used an open-ended question as a qualitative measure for learning intentions. More specifically, we asked the instructors "How will you improve your course in the next semester based on the provided feedback? Please make suggestions". Two independent raters assessed how many distinct ideas for improving their teaching the instructors reported within their answers. Distinct ideas for changes that were formulated very precisely and intentions to change on a more global level were counted (coding options: $0=$ no ideas formulated; $-99=$ missing values due to non-participation in the second questionnaire). If instructors tried to reach one purpose by several precise changes, all diverse purposes were counted. The two raters agreed in $87.6 \%$ of their judgements (Cohens $\kappa=.93$ ). We used the mean of both ratings regarding the absolute number of distinct ideas as a qualitative measure for learning intentions. High scores represent stronger reported intentions to act on the SET-results or a higher number of concrete ideas and thereby learning intentions.

\subsection{Analyses}

As conducting SET(s) was voluntary for the instructors and not all university instructors who would have been able to use the platform (indicated by the reported teaching commitments) did conduct SET(s), we conducted separate analyses for predicting the initiation of learning from SETs by using the platform to conduct SET(s) (pre-action phase of self-regulated learning; full sample) and for the later learning process (action and post-action phase of self-regulated learning; reduced sample). We conducted structural equation models for our main analyses with manifest scores using Mplus Version 7 (Muthén \& Muthén, 1998-2012). We used the maximum likelihood estimator with robust standard errors (MLR) and the weighted least squares means and variance (WLSMV)-adjusted estimator (for analyses with categorical outcomes), which are robust to multivariate non-normality because our data violated the assumption of normal distribution in KolmogorovSmirnov tests for all variables (with the exception of the intention to act). We log transformed the processing time because the time data violated the assumption of normal distribution. We report standardized parameter estimates for better interpretability for all findings. Standardized parameters reflect how many standard deviations an outcome variable changes per standard deviation increase in the predictor variable. For regression coefficients, when we had directed hypotheses, we reported one-tailed levels of significance.

\subsubsection{Missing Values}

We had no missing values on any variables assessed in the baseline questionnaire. However, out of the 152 instructors who conducted SET(s), only 132 also answered the short questionnaire $(13.1 \%$ missing data regarding learning intentions). As we coded the processing time for 19 participants as missing data due to outliers with very high viewing times (see above), we had in total $17.1 \%$ missing data regarding processing time. Finally, some participants had missing values on the indicator for teaching quality for all students that had participated in the SET (1.3\% missing data). We used a full information maximum likelihood approach (FIML) to handle missing data and include all available information for model estimations. This method increases the power of the data analysis and reduces the impact of bias due to missing data (Enders, 2010).

\subsubsection{Pre-Action Phase of Self-regulated Learning}

We estimated two models to assess whether achievement goals predict if the instructors conducted SET(s) using the net sample $(N=407)$. In the first model, we regressed whether instructors had conducted SET(s) as a dichotomous measure on instructors' achievement goals and the two moderator variables (main effects). In the subsequent model, we added the proposed interaction effects of the two moderator variables (beliefs in the validity of SETs; general experienced threat through negative feedback) with learning goals to the model. In both models, we allowed for correlations between all predictor variables (including interaction terms). Both models were fully saturated. 


\subsubsection{Action and Post-Action Phase of Self-regulated Learning}

We estimated one structural equation model to test the mediation hypotheses regarding learning intentions (intention to act and concrete ideas) based on the sub sample $(\mathrm{N}=152)$. More precisely, we regressed both learning outcomes of the post-action phase (intention to act and concrete ideas) on relevant achievement goals of the pre-action phase (learning approach/avoidance goals and work avoidance goals), on the indicator for the action phase (processing time) and on four control variables to control for quantitative and qualitative differences in the feedback instructors received within the SET-results. Additionally, processing time was regressed on the achievement goals and control variables. Indirect effects of achievement goals via processing time on both outcome variables were calculated in this model. We allowed for correlations of the outcome variables (intention to act and concrete ideas) and correlations between all predictor variables (achievement goals and control variables), yielding a fully saturated model.

Participating instructors likely differ in the quality of their teaching and the number of participating students as well as self-generated inquiries. These variables might impact the number and quality of available information to process as well as the number of available recommendations for improvement of teaching. Therefore, we chose to also include teaching quality, number of students, number of evaluated courses, and number of additional questions in the SET as control variables in our SEM. We used absolute numbers of evaluated courses and numbers of additional questions that the instructors themselves added to the evaluation as indicators. For teaching quality, we used a single item of the SEEQ (Marsh, 1982) that is meant to indicate overall teaching quality. More specifically, the students were asked to assign an overall grade to the course ranging from 1 (very good) to 5 (poorly) with low grades indicating good teaching (German grading system). As instructors were free to evaluate multiple courses-we used the average score across the SET(s) instructors conducted within one semester after the baseline questionnaire before answering the short questionnaire and the average number of students participating in the conducted SET(s) for our further analyses.

\section{Results}

The descriptive statistics and correlations are reported in Table 1.

\subsection{Pre-Action Phase of Self-regulated Learning}

As expected, we found positive associations between learning avoidance goals and voluntarily conducted SET(s) in our sample of higher education instructors (see Table 1). This association was robust even when we controlled for the other achievement goals in multivariate analyses (see Table 2, Model 1). However, we found no statistically significant associations for the other achievement goals or the moderator variables, neither in bivariate nor in multivariate analyses. Nevertheless, the associations of conducting SET(s) and performance approach/avoidance goals and work avoidance goals pointed descriptively in the expected direction. Achievement goals and the moderators did not explain a significant proportion of the variance in later voluntarily conducted SET(s) in the multivariate model $\left(R^{2}=.05, p=.075\right)$.

Moreover, we did not find statistically significant moderation effects in the additional model that included the supposedly relevant interactions of beliefs in the validity of SETs and general experienced threat in light of negative feedback with learning goals (see Table 2, Model 2).

\subsection{Action and Post-Action Phase of Self-regulated Learning}

Figure 2 depicts the significant standardized path coefficients derived from the structural equation model on later learning phases. The multivariate model explained substantial amounts of variance for indicators of the action (20\% of processing time, $p=.001$ ) and post-action phases (between 19\% and $20 \%$ for learning intentions, $p \leq .001)$.

Learning (approach and avoidance) goals were not significantly associated with processing time in the multivariate model. As expected, learning approach goals positively predicted later reported learning intentions (operationalized as intention to act on the SET-results and number of concrete ideas to improve teaching), in bivariate and in multivariate analyses. We neither found associations for learning avoidance goals nor for work avoidance goals with later learning 


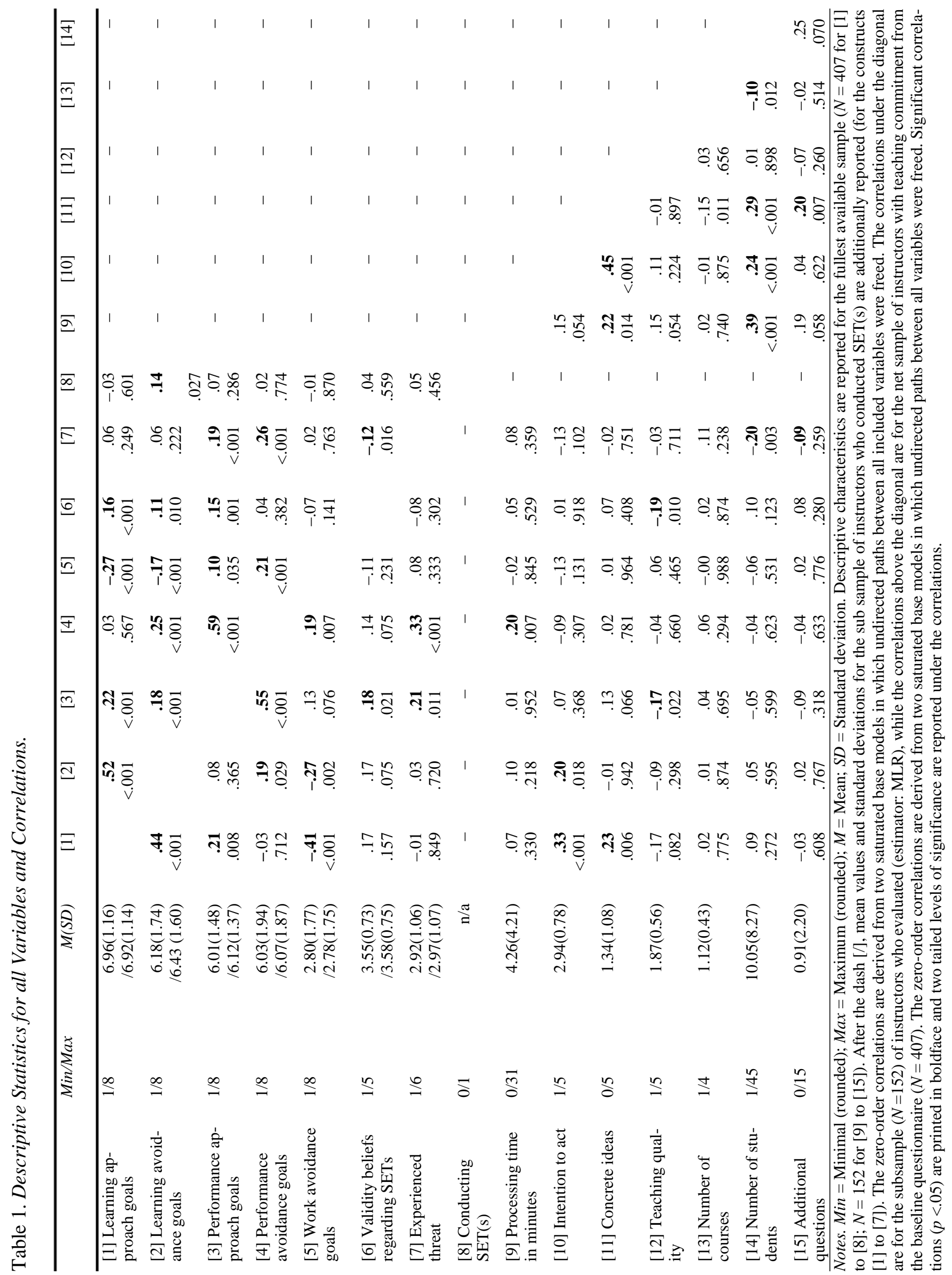


Table 2. Results for Associations with Later Conducted SET(s).

\begin{tabular}{lrrrrrr}
\hline & \multicolumn{3}{c}{ Model 1 } & \multicolumn{3}{c}{ Model 2 } \\
\hline & $\beta$ & \multicolumn{1}{c}{$S E$} & \multicolumn{1}{c}{$p$} & $\beta$ & \multicolumn{1}{c}{$S E$} & $p$ \\
\hline [1] Learning approach goals & -.20 & 0.08 & .994 & -.20 & 0.08 & .993 \\
[2] Learning avoidance goals &. $\mathbf{2 4}$ & 0.08 & .002 &. $\mathbf{2 5}$ & 0.08 & .002 \\
[3] Performance approach goals & .13 & 0.09 & .065 & .13 & 0.09 & .062 \\
[4] Performance avoidance goals & -.13 & 0.09 & .074 & -.13 & 0.09 & .076 \\
[5] Work avoidance goals & -.01 & 0.07 & .457 & -.01 & 0.07 & .455 \\
[M1] Validity beliefs & .03 & 0.06 & .302 & .04 & 0.07 & .292 \\
[M2] Experienced threat & .05 & 0.06 & .801 & .06 & 0.06 & .839 \\
Interaction [M1x1] & - & - & - & -.04 & 0.09 & .658 \\
Interaction [M1x2] & - & - & - & .05 & 0.10 & .324 \\
Interaction [M2x1] & - & - & - & -.10 & 0.07 & .072 \\
Interaction [M2x2] & - & - & - & .04 & 0.07 & .704 \\
\hline$R^{2}$ & \multicolumn{2}{c}{$R^{2}=.05, p=.075$} & $R^{2}=.06, p=.051$ \\
\hline
\end{tabular}

Notes. $\beta=$ standardized regression coefficient; $S E=$ standard error; $p=$ one-tailed level of significance. Significant effects $(p<.05)$ are printed in boldface. The correlations of predictor variables varied between -.27 and .59 in Model 1; and between -.38 and .72 in Model 2 .

outcomes (processing time, learning intentions) under consideration of the learning goals and control variables. The bivariate association of processing time and the number of concrete ideas for improvement of teaching did not emerge when controlling for effects of the considered achievement goals and control variables on learning intentions in the multivariate model. Moreover, we found no indirect effects of the suspected achievement goals via processing time on learning intentions. The indirect effect could not be found for the link of learning approach goals $(\beta=.18, S E=.05, p<$ $.001)$, learning avoidance goals $(\beta=.18, S E=.05, p<$ $.001)$ or work avoidance goals $(\beta=.18, S E=.05, p<$ $.001)$ with intentions to act on SET results. Congruently, no indirect effect of any of the proposed achievement goals on the number of concrete ideas for improvement was statistically significant (learning approach goals: $\beta=.18, S E=.05, p<.001$; learning avoidance goals: $\beta=.18, S E=.05, p<.001$; work avoidance goals: $\beta=.18, S E=.05, p<.001$ ).

Interestingly, teaching quality was positively associated with processing time and intention to act on the SET-results. This means that the worse the teaching quality was rated, the more time it took instructors to process the results and the higher their intention was to act on the results they processed. In addition, the more students participated in the SET, the more time instructors needed to process the results and the higher the number of concrete ideas to improve future teaching were reported by their instructors. Moreover, the number of courses instructors evaluated was negatively associated with the number of ideas for improvement of teaching.

\section{Discussion}

In our longitudinal field study, we aimed to investigate whether and how achievement goals predict self-regulated learning with SETs within university instructors. According to theories of self-regulated learning, we assumed that motivation (indicated by achievement goals) predicts instructors' initiation of learning from SETs by conducting them (pre-action phase), processing the SET-results (action-phase), and building learning intentions for future improvement in teaching (post-action phase). In our study, instructors reported their achievement goals in a baseline questionnaire before evaluating their courses with an online tool, which assessed how much time instructors spent processing. Learning intentions were assessed in a short questionnaire directly after processing the SET-results for the first time. We found that learning avoidance goals predicted the instructors' behavior to voluntarily conduct SET(s). We found no effects for any other achievement goals or any moderations by beliefs in the validity of 


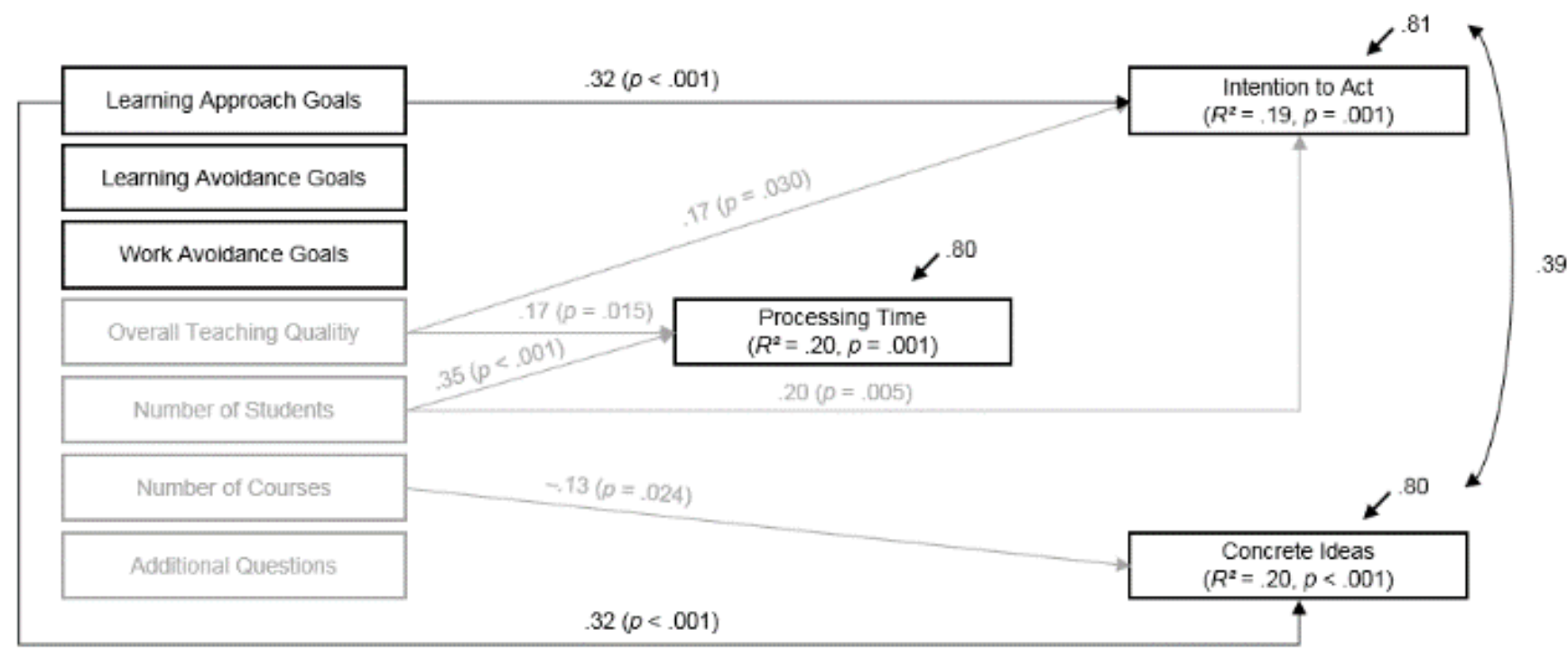

Figure 2. Results of the mediation model for the associations between achievement goals and learning intentions via processing time $(N=152)$. The model was fully saturated (estimator: MLR). Only statistically significant paths are depicted $(p<.05)$. One-tailed significance levels are reported for directed hypotheses (regarding the link between achievement goals and learning intentions via processing time); two-tailed levels of significant are reported for the associations with control variables (depicted in grey). The correlations between the predictor variables varied between -.41 and .44 .

SETs or experienced threat concerning negative feedback on the behavior to voluntarily conduct SET(s). In contrast, learning approach goals predicted later selfreported learning intentions for future teaching that were based on the concrete SET-results. However, the positive association of learning approach goals and learning intention was not mediated by instructors' processing time.

\subsection{Theoretical Implications}

Our study advances research on learning from SET-results, as we proposed a model that explains what motivates instructors to use student evaluations of teaching. Such a model is desperately needed, as the impact of SETs depends on instructors' openness to student feedback and their willingness to engage with the evaluation results (Kember et al., 2002). In line with theories of self-regulated learning, we find that instructors' achievement goals predict necessary learning steps during the pre-action phase (conducting SETs), the action phase (processing of SETs), and the post-action phase (learning intentions). We do not claim that our theoretical framework on motivated SET usage and processing exhaustingly describes all processes that lead instructors to conduct and learn from SETs, as substantial proportions of variance on the criteria are not yet explained. However, we provide a foundation for further research on the subject matter. In this regard, our results underline the crucial importance of learning goals as facilitators of self-regulated learning in- and outside of higher education (Daumiller et al., 2020; Diethert et al., 2015; Hein et al., 2019, 2020; Nitsche et al., 2013).

From a methodological perspective, we contribute to the literature by using behavioral measures such as the actual voluntary use of non-mandatory SETs and processing time to investigate how instructors use SET(s). This results in more realistic estimations of the predictive power of achievement goals than when only relying on self-report measures. This advancement, however, comes with the caveat that we only found small associations of achievement goals with the behavioral indicator of conducting SET(s) and no associations with processing time (except for an unexpected correlation with learning avoidance goals). One possible explanation for this pattern of results is that processing time itself might be limited in its reliability, as there could be multiple reasons why instructors keep the tab with the SET results open (besides looking at them). In contrast, we found associations between learning avoidance goals and the voluntary use of SETs as a second behavioral variable. It is theoretically reasonable that the striving to avoid missing learning opportunities might motivate instructors to use non-mandatory and time extensive SETs. However, it is noteworthy that the amount of explained variance in voluntary conducted 
SET(s) was not significant in our study, albeit the fact that we found a significant positive association between learning avoidance goals and conducting SET(s). To find even a small positive association of teaching-related learning avoidance goals and actually conducting SET(s) as behavioral measure, is highly interesting. There can be several reasons that explain why the amount of explained variance was not significant. It is possible that the effect is very small and was not detected due to a limitation in power. Moreover, the constructs are operationalized on different levels, because we assessed general teaching-related achievement goals instead of concrete SET-related goals. Because the amount of explained variance in the conducted SET was not significant, the practical relevance of the association within the learning steps in the pre-action phase is unclear and should be further investigated in future studies.

Moreover, our design allows for temporal ordering of most of the variables (achievement goals, SET conducted, processing time for SET-results and learning intention for future teaching) and thereby prospective analyses. This helps us to gather an even more cohesive picture about the learning process and to distinguish different phases in line with models of self-regulated learning. The depicted process underlines the validity of such models. Without deciding to use SETs and conducting them, instructors have no chance to interpret the results or to form learning intentions to improve future teaching. Despite a lack of predictive power when additionally considering achievement goals, we found that processing time was indeed predictive for the numbers of derived ideas to further one's teaching in bivariate analyses. This clearly speaks to the notion that the processes in the action phase may also be important for post-action reflection processes.

Finally, our results strengthen the claim of the predictive power of learning approach goals for the self-regulated learning processes, congruent with prior research on instructors' professional learning (Daumiller et al., 2020; Hein et al., 2019). In our study, learning approach goals predicted later learning intentions that were based on concrete SETs that were just processed. This study improved the measure of the outcome variable of the post-action phase by including a quantitative and qualitative assessed measure of learning intention. The connection of learners' motivation in the pre-action phase and learning intentions formulated in the post-action phase remained robust when controlling for processing time (action phase), teaching quality, and indicators for the amount of received information.

\subsection{Implications for Educational Practices}

Research that sheds light on antecedents of learning from SET-results and the learning process can provide relevant practical implications. As such, fostering learning (approach) goals might be helpful for promoting self-reported learning in higher education instructors' learning from SETs. However, as instructors already report high learning approach goals (compared to the midpoint of the scale) and SETs are mostly conducted mandatorily in higher education institutions (pre-action phase), it might be beneficial to support instructors in the following steps of the learning process (action and post-action phase) to improve professional learning from SETs in educational practice. To support instructors in building learning intentions to improve future teaching (in the post-action phase), didactical courses might promote the intention to act on SETs for further improvement (e.g. discuss results with colleagues and students, consider changes in future courses, and participate in relevant didactical trainings). Instead of only informing instructors about the SETs in higher education institutions, concrete ideas for improvement of teaching might be promoted by encouraging instructors to reflect on their SETs with a short qualitative survey on their SETs and their goals for future teaching (What do they learn from the SETs? What do they want to improve in their future teaching and how could they do that?). However, our study does not provide evidence for the causality of the found associations or the consequences of learning intentions for the quality of teaching. For this reason, the practical ideas need to be tested in intervention studies before they can be implemented into higher education systems.

\subsection{Limitations and Future Directions}

Against our hypotheses, we did not find performance goals or work avoidance goals to predict the behavior to conduct SET(s). This could, however, be a direct effect of our acquisition strategy that relied on the willingness of instructors to participate in a study where they were meant to interact with SETs. This in itself is a motivated action and instructors with low or sup-optimal motivation could have been more likely to not participate in the study at all, limiting our ability to detect effects of this goal class. The observed means for achievement goals speak in this direction: Learning approach goals were descriptively slightly stronger, while performance avoidance goals were slightly weaker within our sample compared to previous research with 
less extensive study designs (e.g. compared to a crosssectional study by Daumiller et al., 2019). Therefore, it could be highly beneficial to investigate the process of learning from SET-results in a less pre-selected sample of instructors in future research. A more economic design to replicate and advance our findings could be to question university instructors at the beginning of their semester about motivational variables, beliefs, and fears and then measure relevant outcome variables after they processed their obligatory (rather than non-mandatory) SET-results.

In our study, we mostly focused on the learning process at the beginning rather than on the future learning result. Due to the complex sample (different countries, multiple universities, and different departments), we did not have access to additional objective measures of teaching advancement besides self-reported intentions for future improvement in teaching. In future research, this limitation could be overcome by focusing on instructors' concrete goals to improve future teaching based on SETs and assess their goal attainment in subsequent semesters by self-ratings and external ratings of students or colleagues.

Finally, our results indicate temporal trends, however, they cannot tackle the question of causality, which calls for further experimental studies. In such studies, it would be interesting to investigate how researchers perceive and interact with SETs depending on prior induced achievement goals. In a naturalistic design, the instructors could be briefed to bring their own SETs, while a less extensive solution could be to provide them with vignettes of fictional SETs.

Feedback theories and self-regulated learning provide frameworks to look into instructors' learning from student feedback in future research. Research on student learning provide evidence that the least complex feedback was beneficial for learners in terms of efficiency and learning outcomes (Kulhavy et al., 1985). As the complexity of SET-results is quite high, reducing the complexity of SETs or helping to interpret complex student feedback might be beneficial for instructors' learning outcomes. This would be of high interest for future research and of practical significance for how to provide SET-results in the evaluation process in higher education institutions. Furthermore, future research could focus on reasons and concrete goals to use SETs to predict the usage of SET(s) and learning from its results.

\section{Conclusion}

The present study provides new insights into higher education instructors' usage and learning from student evaluations of teaching. Our results support that especially learning goals play an important role in predicting if instructors voluntarily conduct SETs and in predicting their intention to act on the SETs. Understanding the impact of professional motivation of higher education instructors on the processing and use of SETs is crucial in fostering instructors' professional development in teaching. All in all, the ideas presented in this article provide the foundation for future research on instructors' learning from SET-results with the goal of advising higher education institutions, instructors, and quality management on how to support instructors in seeing SETs as valuable learning opportunities.

\section{References}

Achtziger, A., \& Gollwitzer, P. M. (2018). Motivation and volition in the course of action. In J. Heckhausen, \& $\mathrm{H}$. Heckhausen, Motivation and Action (pp. 485-527). Springer.

Ajzen, I. (1991). The theory of planned behavior. Organizational Behavior and Human Decision Processes, 50(2), 179-211.

Barba, P. G. de, Kennedy, G. E., \& Ainley, M. D. (2016). The role of students' motivation and participation in predicting performance in a MOOC. Journal of Computer Assisted Learning, 32(3), 218-231. https://doi.org/10.1111/jcal.12130

Boud, D., \& Molloy, E. (2013). Rethinking models of feedback for learning: The challenge of design. Assessment \& Evaluation in Higher Education, 38(6), 698-712. https://doi.org/10.1080/02602938.2012.691462

Butler, D. L., \& Winne, P. H. (1995). Feedback and self-regulated learning: A theoretical synthesis. Review of Educational Research, 65(3), 245-281. https://doi.org/10.3102/00346543065003245

Butler, R. (2012). Striving to connect: Extending an achievement goal approach to teacher motivation to include relational goals for teaching. Journal of Educational Psychology, 104(3), 726-742. https://doi.org/10.1037/a0028613

Butler, R. (2014). What teachers want to achieve and why it matters: An achievement goal approach to teacher motivation. In P. W. Richardson, S. A. Karabenick, \& H. M. G. Watt (Eds.), Teacher Motivation: Theory and Practice (pp. 20-35). Routledge.

Butler, R., \& Shibaz, L. (2008). Achievement goals for teaching as predictors of students' perceptions of instructional practices and students' help seeking and cheating. Learning and Instruction, 18(5), 453-467. https://doi.org/10.1016/j.learninstruc.2008.06.004 
Cerasoli, C. P., Alliger, G. M., Donsbach, J. S., Mathieu, J. E., Tannenbaum, S. I., \& Orvis, K. A. (2018). Antecedents and Outcomes of Informal Learning Behaviors: A MetaAnalysis. Journal of Business and Psychology, 33(2), 203-230. https://doi.org/10.1007/s10869-017-9492-y

Choi, W., \& Jacobs, R. L. (2011). Influences of formal learning, personal learning orientation, and supportive learning environment on informal learning. Human Resource Development Quarterly, 22(3), 239-257. https://doi.org/10.1002/hrdq.20078

Cury, F., Elliot, A. J., Da Fonseca, D., \& Moller, A. C. (2006). The social-cognitive model of achievement motivation and the $2 \times 2$ achievement goal framework. Journal of Personality and Social Psychology, 90(4), 666. https://doi.org/10.1037/0022-3514.90.4.666

Daumiller, M., Dickhäuser, O., \& Dresel, M. (2019). University instructors' achievement goals for teaching. Journal of Educational Psychology, 111(1), 131-148. https://doi.org/10.1037/edu0000271

Daumiller, M., Rinas, R., Olden, D., \& Dresel, M. (2020). Academics' motivations in professional training courses: Effects on learning engagement and learning gains. International Journal for Academic Development, 0(0), 1-17. https://doi.org/10.1080/1360144X.2020.1768396

Daumiller, M., Stupnisky, R., \& Janke, S. (2020). Motivation of higher education faculty: Theoretical approaches, empirical evidence, and future directions. International Journal of Educational Research. 99, 101502. https://doi.org/10.1016/j.ijer.2019.101502

Diethert, A. P., Weisweiler, S., Frey, D., \& Kerschreiter, R. (2015). Training motivation of employees in academia: Developing and testing a model based on the theory of reasoned action. In J. Gorges, A. Gegenfurtner, \& H. Kuper (Hrsg.), Motivationsforschung im Weiterbildungskontext (S. 29-50). Springer Fachmedien. https://doi.org/10.1007/978-3-658-06616-1_3

Elliot, A., \& Church, M. A. (1997). A hierarchical model of approach and avoidance achievement. Journal of Personality and Social Psychology, 72, 218-232. https://doi.org/10.1037/0022-3514.72.1.218

Enders, C. K. (2010). Wrapping Things Up - Some Final Practical Considerations. In Applied Missing Data Analysis, edited by C. K. Enders, 329-344. New York: Guilford Press.

Gaab, J. (2009). PASA-Primary appraisal secondary appraisal. Verhaltenstherapie, 19(2), 114-115.

Hein, J., Daumiller, M., Janke, S., Dresel, M., \& Dickhäuser, O. (2019). How learning time mediates the impact of university Scholars' learning goals on professional learning in research and teaching. Learning and Individual Differences, 72, 15-25. https://doi.org/10.1016/j.lindif.2019.04.002
Hein, J., Janke, S., Daumiller, M., Dresel, M., \& Dickhäuser, O. (2020). No learning without autonomy? Moderators of the association between university instructors' learning goals and learning time in the teaching-related learning process. Learning and Individual Differences, 83-84, 101937. https://doi.org/10.1016/j.lindif.2020.101937

Hornstein, H. A. (2017). Student evaluations of teaching are an inadequate assessment tool for evaluating faculty performance. Cogent Education, 4(1), 1304016. https://doi.org/10.1080/2331186X.2017.1304016

Hulleman, C. S., Schrager, S. M., Bodmann, S. M., \& Harackiewicz, J. M. (2010). A meta-analytic review of achievement goal measures: Different labels for the same constructs or different constructs with similar labels? Psychological Bulletin, 136(3), 422-449. https://doi.org/10.1037/a0018947

Ivanic, R., Clark, R., \& Rimmershaw, R. (2000). What am I supposed to make of this?: The messages conveyed to students by tutors' written comments. In M. Lea \& B. Stierer (Hrsg.), Student writing in higher education: New contexts (S. 47-65). Open University Press. https://eprints.lancs.ac.uk/id/eprint/8586/

Janke, S., \& Dickhäuser, O. (2018). A situated process model of vocational achievement goal striving within members of the academic staff at university. Motivation and Emotion, 42(4), 466-481. https://doi.org/10.1007/s11031017-9657-z

Janke, S., Hein, J., Daumiller, M., Rinas, R., Erdfelder, E., Dresel, M. \& Dickhäuser, O. (2020, in press). Open Access Evaluation: Lehr-Evaluation-Online (LEO) als Instrument zur studentischen Lehrveranstaltungsevaluation [Open Access Evaluation: Teaching Evaluation Online (LEO) as an Instrument for Student Course Evaluation]. Qualität in der Wissenschaft.

Kaplan, A., \& Maehr, M. L. (2007). The Contributions and Prospects of Goal Orientation Theory. Educational Psychology Review, $19 \quad$ (2), $141-184$. https://doi.org/10.1007/s10648-006-9012-5

Kember, D., Leung, D. Y. P., \& Kwan, K. P. (2002). Does the Use of Student Feedback Questionnaires Improve the Overall Quality of Teaching? Assessment \& Evaluation in Higher Education, 27(5), 411-425. https://doi.org/10.1080/0260293022000009294

Kulhavy, R. W., White, M. T., Topp, B. W., Chan, A. L., \& Adams, J. (1985). Feedback complexity and corrective efficiency. Contemporary Educational Psychology, 10(3), 285-291. https://doi.org/10.1016/0361-476X(85)90025-6

Kücherer, B., Dresel, M., \& Daumiller, M. (2020). Relationship between achievement goals and attention of university instructors in higher education professional training courses. Higher Education, Skills and Work-Based Learning.

Marsh, H. W. (1982). Seeq: A Reliable, Valid, and Useful Instrument for Collecting Students' Evaluations of University Teaching. British Journal of Educational Psychology, 52(1), 77-95. https://doi.org/10.1111/j.20448279.1982.tb02505.x 
Marsh, Herbert W. (1984). Students' evaluations of university teaching: Dimensionality, reliability, validity, potential baises, and utility. Journal of Educational Psychology, 76(5), 707-754. https://doi.org/10.1037/00220663.76.5.707

Marsh, Herbert W., \& Roche, L. (1993). The Use of Students' Evaluations and an Individually Structured Intervention to Enhance University Teaching Effectiveness. American Educational Research Journal, 30(1), 217-251. JSTOR. https://doi.org/10.2307/1163195

Molloy, E., \& Boud, D. (2013). Changing conceptions of feedback. In D. Boud, \& E. Molloy, E. (Eds.), Feedback in higher and professional education: understanding it and doing it well. Routledge.

Nicol, David J., \& Macfarlane-Dick, D. (2006). Formative assessment and self-regulated learning: A model and seven principles of good feedback practice. Studies in Higher Education, 31(2), 199-218. https://doi.org/10.1080/03075070600572090

Nitsche, S., Dickhäuser, O., Fasching, M. S., \& Dresel, M. (2013). Teachers' professional goal orientations: Importance for further training and sick leave. Learning and Individual Differences, 23, 272-278. https://doi.org/10.1016/j.lindif.2012.07.017

Nowakowski, A., \& Hannover, B. (2015). Wie Lehrende die Ergebnisse studentischer Evaluationen wahrnehmen: Eine experimentelle Manipulation qualitativer und quantitativer Rückmeldungskomponenten. [How teachers perceive the results of student evaluations: An experimental manipulation of qualitative and quantitative feedback components.] Diagnostica, 61(3), 144-152. https://doi.org/10.1026/0012-1924/a000144

Payne, S. C., Youngcourt, S. S., \& Beaubien, J. M. (2007). A meta-analytic examination of the goal orientation nomological net. Journal of Applied Psychology, 92(1), 128-150. https://doi.org/10.1037/0021-9010.92.1.128

Retelsdorf, J., Butler, R., Streblow, L., \& Schiefele, U. (2010). Teachers' goal orientations for teaching: Associations with instructional practices, interest in teaching, and burnout. Learning and Instruction, 20(1), 30-46. https://doi.org/10.1016/j.learninstruc.2009.01.001
Rinas, R., Dresel, M., Hein, J., Janke, S., Dickhäuser, O., \& Daumiller, M. (2020). Exploring University Instructors' Achievement Goals and Discrete Emotions. Frontiers in Psychology,

11. https://doi.org/10.3389/fpsyg.2020.01484

Schmitz, B., \& Wiese, B. S. (2006). New perspectives for the evaluation of training sessions in self-regulated learning: Time-series analyses of diary data. Contemporary Educational Psychology, 31(1), 64-96. https://doi.org/10.1016/j.cedpsych.2005.02.002

Serin, H. (2019). Student Evaluations of Teaching Effectiveness: An Instrument to Increase Teaching Quality in Higher Education. International Journal of Social Sciences \& Educational Studies, 5(4), 168-173. DOI: 10.23918/ijsses.v5i4p168

Spooren, P., \& Mortelmans, D. (2006). Teacher professionalism and student evaluation of teaching: Will better teachers receive higher ratings and will better students give higher ratings? Educational Studies, 32(2), 201-214. https://doi.org/10.1080/03055690600631101

Wagenaar, T. C. (1995). Student Evaluation of Teaching: Some Cautions and Suggestions. Teaching Sociology, 23(1), 64-68. JSTOR. https://doi.org/10.2307/1319382

Watson, C., Seifert, A., \& Schaper, N. (2018). Die Nutzung institutioneller Lerngelegenheiten und die Entwicklung bildungswissenschaftlichen Wissens angehender Lehrkräfte. Zeitschrift für Erziehungswissenschaft, 21(3), $565-588$.

Zhao, J., \& Gallant, DorindaJ. (2012). Student evaluation of instruction in higher education: Exploring issues of validity and reliability. Assessment \& Evaluation in Higher Education, 37(2), 227-235. https://doi.org/10.1080/02602938.2010.523819

Zimmerman, B. J. (2000). Attaining self-regulation: A social cognitive perspective. In Handbook of Self-regulation (S. 13-39). Elsevier.

Note. This is a pre-copyedited, author-produced PDF of an article submitted for publication. This paper is not the copy of record and may not exactly replicate the final, authoritative version of the article. The final article will be available, upon publication, via its DOI. 